\title{
NOTAS PTERIDOLOGICAS
} (27)

\section{Notas PTERIDOLOGiCAS DEL VALLE DEL JALON}

Adrián ESCÚDERO (1), Andrés MOLINA (1) \& Agustín RUBIO SANCHEZ (2)

El río Jalón atraviesa el Sistema Ibérico entre las sierras de la Virgen y Nicort encajándose en un desfiladero, en ocasiones muy abrupto, que se extiende desde la antigua Bilbilis, al norte de Calatayud, hasta las inmediaciones de Ricla, ya en plena depresión del Ebro.

Los materiales que configuran el desfiladero están formados por calizas mesozoicas, que se disponen a la entrada y salida del mismo, aflorando en el centro las cuarcitas paleozoicas que componen el núcleo central del Sistema Ibérico septentrional.

Los paredones y cantiles del desfiladero constituyen un magnífco refugio de gran cantidàd de táxones de óptimo termomediterráneo levantino, que han logrado penetrar al interior de la península a favor de estos accidentes en épocas pretéritas de carácter más cálido, quedando en la actualidad acantonados en estas localidades con carácter relíctico.

En esta primera nota damos a conocer una serie de pteridófitos, de carácter netamente termófilo, alguno de los cuales representan notables disyunciones respecto de las poblaciones homólogas más cercanas, constituyendo nuevas aportaciones a la flora aragonesa.

Asplenium petrarchae (Guérin) DC. subsp. petrarchae

ZARAGOZA: Purroy; fisuras de rocas calizas en exposición S. 30TXL2192; 600 m; Pajarón, Muñoz, Rubio, Escudero \& Molina 14-V-1990; MACB 34301. Roquedos calizos entre Calatayud y Huérmeda, 540 m; 30TXL1682; Molina, Escudero \& Rubio 7-V-1990; MACB 34300.

Interesante taxon termófilo, característico de Asplenion petrarchae, ya recolectado con anterioridad en el valle, y del que únicamente se aportan nuevas localidades. 
Cheilanthes acrostica (Balbis) Tod.

ZARAGOZA: Roquedos calizos entre Morés y Saviñán, a 2 Km de Saviñán; 550 m; 30TXL2091; Escudero, Rubio \& Molina 7-V-1990; MACB 34297. Purroy, fisuras de rocas calizas en exposición S; 600 m; 30TXL2192; Pajarón, Muñoz, Rubio, Escudero \& Molina 14-V-1990; MACB 34295. Roquedos calizos entre Calatayud y Huérmeda, 540 m; 30TXL1682; Escudero, Molina \& Rubio 7-V-1990, MACB 34296. Embid de la Ribera; cuarcitas en exposición S; 550 m; 30TXL1786; Escudero \& Muñoz 2-VI-1990; MACB 34591.

Frecuente sobre calizas caldeadas en todo el desfiladero, si bien puede aparecer esporádicamente sobre sustratos cuarcíticos, tal y como ocurre en las proximidades de Embid de la Ribera.

Aunque Morales \& Fernández-Casas (1989) no incluyen localidades aragonesas de esta especie, a ésta deben de referirse todas las localidades zaragozanas incluidas por ellos en C. maderensis (Op. cit.: 67), posiblemente como consecuencia de una mala interpretación de la complicada sinonimia de las especies del género, máxime después de consultadas las últimas monografías al respecto (Saenz de Rivas \& Rivas-Martínez 1979; Muñoz Garmendia 1986).

\section{Cheilanthes maderensis Lowe}

ZARAGOZA: Embid de la Ribera; cuarcitas en exposición S; 550 m; 30TXL1786; Molina, Pajarón, Muñoz, Rubio \& Escudero 14-V-1990 MACB 345892. ibid, Escudero \& Muñoz 2-VI-1990; MACB 34590.

Taxon muy raro en el territorio, donde presenta un comportamiento exclusivamente silicícola. Se distingue muy bien del resto de las especies del género con las que convive por sus pínnulas completamente glabras y el pseudoindusio de margen entero.

Teniendo en cuenta lo expuesto en la especie anterior se trata de una novedad para la flora aragonesa.

\section{Cheilanthes tinaei Tod.}

ZARAGOZA: Embid de la Ribera; cuarcitas en exposición S; 550 m; 30TXL1786; Molina, Pajarón, Muñoz, Rubio \& Escudero 14-V-1990 MACB 34294.

Abundante de manera local, y de comportamiento idéntico a la especie anterior, con la que convive. Del mismo modo también constituye una novedad para la flora aragonesa.

Cosentinia vellea (Aiton) Tod. subsp. bivalens (Reichstein) Rivas-Martínez \& Salvo

ZARAGOZA: Roquedos calizos entre Morés y Saviñán, a 2 Km de saviñán; 550 m; S; 30TXL2091; Rubio, Escudero \& Molina 7-V-1990; MACB 34299. Roquedos calizos junto a Morés, ermita de San Félix; 500 m; S; 30TXL1993; Rubio, Escudero \& Molina 7-V-1990; MACB 34298.

Taxon no reconocido como independiente por Muñoz Garmendia (1986), y que sin embargo se diferencia muy bien de la subespecie tipo, tetraploide, por el diámetro ecuatorial de las esporas, que resulta ser significativamente menor (Badré \& 
Reichstein, 1983). Siguiendo la metodología empleada por éstos hemos obtenido para las dos poblaciones unos valores del diámetro ecuatorial de $50.3 \mu \mathrm{m}( \pm 2.7)$ para la primera y de $50.3 \mu \mathrm{m}( \pm 1.6)$ para la segunda, valores que son todavía menores que los obtenidos por estos autores.

Se trata de una especie extremadamente rara a la vez que poco abundante, y con un claro significado relíctico en el territorio. Las poblaciones estudiadas representan una notable penetración hacia el interior del valle del Ebro frente a las levantinas más próximas, distantes más de $250 \mathrm{Km}$ en línea recta.

Se localiza en situaciones extremadamente térmicas, y con un comportamiento exclusivamente calcícola, acompañada por todo un cortejo de elementos termomediterráneos, de carácter relíctico en los bordes de la depresión del Ebro, como Piptatherum coerulescens (Desf.) Beauv.; Lavatera maritima Gouan; Ephedra fragilis Desf. subsp. fragilis; Olea europaea L. var. sylvestris Brot.

\section{B I B L I O G R A F I A}

BADRE, F. \& REICHSTEIN, T. -1982- The two cytotypes of Notholaena lanuginosa (Sinopteridaceae, Pteridophyta). Willdenowia, 13:361-367.

MORALES, M.J. \& FERNANDEZ CASAS, J. -1989- Cheilanthes maderensis Tod. Mapa 290 in Fernández Casas, J. (Ed). Asientos para un atlas corológico de la Flora occidental 14. Fontqueria, 25:1-201.

MUÑOZ GARMENDIA, F. -1982- Cheilanthes in Castroviejo, S., et al. Eds. Flora Ibérica, 1:44-51. Madrid.

SAENZ DE RIVAS, C. \& RIVAS MARTINEZ, S. -1979- Revisión del género Cheilanthes (Sinipteridaceae) en España. Lagascalia, 8(2):215-241.

(Aceptado para su publicación el 3 de julio de 1990)

Dirección de los autores: (1): Dpto. Biología Vegetal I (Botánica) U.C.M. 28040 Madrid. (2): Dpto. Silvopascicultura. E.T.S.I. Montes. U.P.M. 28040 Madrid. 